\title{
La familia, las relaciones afectivas y la identidad étnica entre indígenas migrantes urbanos en San Luis Potosí
}

\author{
Mónica Lizbeth Chávez González* \\ CIESAS-NORESTE
}

El objetivo de este artículo es debatir en torno al papel que desempeña la familia y las relaciones afectivas en la construcción de la pertenencia étnica en el caso de indígenas que han migrado a la ciudad. Básicamente se abordan los dilemas de reproducción étnica de tének y nahuas fuera de sus lugares de origen para explicar el peso que adquieren las dimensiones subjetivas en la conformación de la identidad étnica.

(Identidad étnica, familias, relaciones afectivas, indígenas migrantes urbanos)

\section{INTRODUCCIÓN}

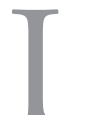

a información y el análisis que se presenta a continuación forman parte de un trabajo de investigación antropológico realizado entre el 2006 y el 2010. Esta investigación tuvo como objetivo primordial analizar el papel de la socialización en la reproducción étnica de indígenas que vivían de forma dispersa en la capital potosina (Chávez 2010). Las dinámicas de socialización se analizaron dentro de dos escenarios de interacción cotidiana: la escuela y la familia. La discusión aquí presente pretende profundizar en la relación que guarda este último ámbito con la identidad étnica; sin embargo, debido a que la escolarización también fue un eje de análisis importante los casos seleccionados corresponden a profesionistas que tuvieron trayectorias educativas más o menos prolongadas.

*mochago@hotmail.com 
En este trabajo se combina el análisis sociodemográfico, la etnografía y la reconstrucción de narrativas biográficas. Para ello se consultaron las bases de datos sobre población hablante de lengua indígena (PHLI) del Instituto Nacional de Estadística y Geografía (INEGI) para el caso de San Luis Potosí; la información recabada se contrastó con las entrevistas realizadas a profesionistas tenek y nahuas así como las observaciones llevadas a cabo en sus espacios de trabajo, hogares y los lugares de origen de estos colaboradores durante el año 2007-2008. En este mismo periodo se realizó la reconstrucción de historias de vida de familias completas asentadas actualmente en la capital, las cuales se trabajaron como estudios de caso, dos de los cuales se presentan en este artículo.

El texto se divide en cuatro partes. En la primera se dialoga con los autores y las perspectivas teóricas que alimentan el análisis. Posteriormente se realiza una breve caracterización sociodemográfica de los indígenas en la capital potosina haciendo énfasis en las particularidades de los tének y nahuas, en el tipo de ocupaciones laborales que desempeñan así como su patrón de asentamiento urbano, aspectos que sin duda tienen que ver con las transformaciones en cuanto a su adscripción étnica. En la siguiente parte se presentan los casos de dos familias de profesionistas - una tének y otra nahua- cuyas trayectorias de vida representan la compleja relación que guardan las relaciones familiares y la afectividad en la reconfiguración étnica de los indígenas urbanos. Ambas familias son originarias de la Huasteca potosina que actualmente residen en la capital del mismo estado. Finalmente se presentan algunas reflexiones finales que pretenden abrir ventanas de discusión sobre la importancia de abordar las múltiples formas de vivir étnicamente la ciudad.

\section{LA FAMILIA Y EL AFECTO EN RELACIÓN A LA IDENTIDAD ÉTNICA}

Dentro de la vasta literatura sobre la identidad étnica, el tema de la familia y los lazos de parentesco ha sido sumamente abordado, no así el del sentido que adquiere la afectividad en este proceso. Gran parte de las investigaciones antropológicas sobre grupos étnicos par- 
ten del carácter corporativo de la familia y de la presencia de unidades domésticas para hacer frente al trabajo agrícola, donde predominan los intereses colectivos sobre los individuales. El parentesco ocupa así un lugar privilegiado ya que estructura gran parte de las dinámicas al interior de las comunidades campesinas y provoca el desarrollo de lazos de solidaridad que explican el funcionamiento de las mismas.

Sin embargo, las familias no sólo sostienen la organización económica y política de los grupos étnicos, sino también generan filiaciones, vínculos y afectividades que contribuyen a definir significados válidos para la conformación identitaria, aun fuera de los contextos de organización campesina. Las ideas vertidas por Epstein en 1978 han sido un parteaguas en el tratamiento de estos temas. En su obra Ethos and Identity abordó el peso de lo afectivo como elemento cohesionador para contrarrestar el enfoque de los grupos étnicos como grupos de intereses que en ese momento desarrollaban Glazer y Moynahan (1975). Para este autor, no toda acción derivada de la identidad étnica proviene de un cálculo racional, ya que hay factores subjetivos que constriñen casi de manera inconsciente el accionar de los individuos. Una nueva categoría étnica surge cuando un grupo es reconocido socialmente por su condición de segregado y cuando de éste emerge una conciencia de convivencias compartidas. No obstante, los grupos étnicos no sólo se conforman por categorías sociales atribuidas externamente, sino que hay aspectos que llevan a los individuos a desarrollar determinadas percepciones de sí mismos y a experimentar fuerzas afectivas que los cohesionan.

Para Bartolomé (1997), esta afectividad es un sentimiento que despierta la presencia de otros con los cuales es posible identificarse por considerarlos semejantes a nosotros mismos. Las formas culturales compartidas, como la lengua o la comida se vuelven lazos comunicativos que vinculan a individuos con una fuerte carga emotiva, vinculación que se muestra en términos de lealtad entre los miembros de un grupo étnico. Así, los comportamientos informales entre los individuos de un mismo grupo, los sentimientos, las preferencias, las emociones que se derivan del contacto con cierto tipo de 
personas, son los aspectos en los que descansa la emotividad. La relación entre pares de un grupo étnico genera en los individuos calma y seguridad frente a la desconfianza o angustia que generan otras relaciones. Esto es lo que Epstein denomina la "cultura íntima" la cual se expresa de manera muy sutil en la vida cotidiana de los sujetos y que se genera casi de manera inconsciente, no a través de discursos explícitos que denotan una etnicidad en acción.

La capacidad aglutinadora de la identidad étnica descansa precisamente en su contenido afectivo, que surge por compartir un universo moral, simbólico y representaciones sociales que la hacen convertirse en una lealtad primordial y totalizadora. Y es precisamente la familia, como ámbito de socialización primaria y por lo tanto primera referencia sobre el mundo, la que teje con mayor fuerza esos vínculos afectivos mediante una interacción cotidiana y prolongada de sus miembros.

En este sentido, la familia representa un ámbito social y cultural históricamente situado donde existen procesos de negociación y reproducción de varias dimensiones de la vida (económicas, sociales, políticas, culturales) mediante la interacción cotidiana y generacional. Además implica la conformación de cierto tipo de relaciones materiales, simbólicas y afectivas entre las que se establecen roles de género, pautas de intercambio, autoridad, solidaridad, entre otras (Salvia 1995). Es un espacio donde confluye lo social y lo individual, en ella se articulan ambas dimensiones y se percibe el carácter relacional de cada una. Lo social se hace presente ya que en la familia se materializan las condiciones estructurales de tipo económico, cultural, político, etcétera, que afectan las funciones y las relaciones internas de los miembros, aunque esto también ocurre a la inversa, ya que las acciones pueden modificar las condiciones macro en las que se inserta la familia. Por otro lado, la familia también está conformada por sujetos con trayectorias particulares de vida que conforman un campo de relaciones interpersonales siempre inestable y en conflicto. Uno de los aspectos donde se percibe este dinamismo entre lo social y lo individual está presente en las situaciones coyunturales, las cuales provienen de circunstancias macro pero que obliga a una toma de decisiones o a un ajuste inconsciente entre los miem- 
bros de la familia. Los procesos migratorios representan estos momentos coyunturales que afectan al grupo familiar.

La problemática de los grupos indígenas migrantes, que se ha caracterizado en los últimos años por ser de tipo rural-urbano o bien rural-rural agroindustrial dentro y fuera del país, ha retomado la discusión del papel que juegan las fronteras simbólicas y afectivas en la resignificación identitaria. El concepto de comunidad moral -retomado de Weber y Cohen principalmente- ha sido empleado para enfatizar que un grupo étnico puede permanecer más allá de sus movimientos territoriales. No es el carácter aislado ni homogéneo el que asegura la reproducción de una comunidad, sino la definición constante de fronteras simbólicas que aglutinan a un colectivo de individuos aun cuando sus condiciones materiales de vida se transforman debido al proceso migratorio. La comunidad se reconstruye fuera de los límites territoriales de origen gracias a la reproducción de rituales e interacciones cotidianas que dotan de sentido a las fronteras étnicas mediante una fuerte carga afectiva (Martínez y De la Peña 2002). Estos indígenas que "se niegan a renunciar a su pertenencia afectiva" recrean así sus rituales a partir de negociaciones entre los mismos miembros de la comunidad. Estos rituales, interacciones y negociaciones se dan a través de las redes de paisanazgo o parentesco que involucran a los miembros que comparten tanto la condición de migrantes como de residentes en el lugar de origen. Necesariamente todo el simbolismo que aglutina cultural y afectivamente a un grupo pasa por el filtro de las relaciones de parentesco o familiares, dicho en otras palabras, las relaciones familiares median las negociaciones que en el día a día enfrentan los individuos para su reproducción como comunidad.

Para el caso de los migrantes, el peso de las familias en la organización de la vida cotidiana es sumamente importante, ya que dentro de ella se hace frente al extrańamiento y a la desterritorialización que caracteriza su condición. Una vez ubicados fuera de sus comunidades, los individuos echan mano de la organización y dinámica familiar para dar orden a sus vidas. El sistema de parentesco que opera dentro de la familia funciona como el primer modo de organización con el que los migrantes indígenas cuentan para hacer frente a las 
nuevas dinámicas en sus contextos receptores. Esto se explica también por los vínculos de lealtad y reciprocidad así como los altos grados de confianza y de afectividad que posee la familia con respecto a otras formas de organización (Ariza 2002). La familia por otro lado, configura las redes sociales de parentesco en una situación de movilidad lo cual asegura un sentido de permanencia y continuidad con los lugares de origen. Para Laura Velasco (2005) estas redes permiten la rearticulación simbólica de la comunidad étnica en la migración.

En este sentido, la familia se convierte en un referente objetivo y subjetivo de la experiencia de movilidad territorial. Es un referente subjetivo porque llega a ser el núcleo central en la interpretación que hacen los indígenas migrantes sobre sus propias experiencias migratorias. A veces las situaciones familiares se convierten en la causa principal para la movilidad (Malkin 1997).

En el caso de la migración urbana, los indígenas suelen experimentar cambios en las estructuras y funciones familiares, por ejemplo, se llegan a conformar matrimonios mixtos, hay una mayor incorporación de los miembros al trabajo asalariado y los hijos experimentan una socialización urbana que sin duda trastoca sus referentes identitarios. Los dilemas de la reproducción étnica en la ciudad se perciben con mayor intensidad en el seno de las relaciones familiares, las cuales se caracterizan por las tensiones, las posiciones encontradas y las rupturas generacionales. Es por ello que los trabajos sobre indígenas urbanos que atienden al tema de la reproducción étnica se enfocan en las unidades familiares y redes de parentesco o paisanazgo (Romer 2003; Rojas 2006; Durin 2006; Chávez 2010). Marta Romer ha sido una de las primeras autoras en señalar que en la transmisión identitaria si existe una relación afectiva positiva entre padres e hijos por lo regular hay una identidad aceptada, en cambio si hay conflictos derivados de situaciones como el alcoholismo o la violencia, los hijos socializados en estas familias tienden a negar o devaluar la identidad étnica.

Por lo regular, las redes familiares de los indígenas urbanos suelen ser muy amplias, como en el caso de los grupos congregados. Pero en otros no es así, ya que en algunas ciudades (de la región no- 
reste del país como Monterrey y San Luis Potosí) hay un gran número de unidades familias nucleares que viven dispersas en diferentes colonias o bien hay individuos (principalmente mujeres) que viven de forma aislada en casa de sus empleadores (refiriéndome al servicio doméstico) (Durin 2008, 2009). Al abordar el caso de las familias nucleares indígenas establecidas en la ciudad no pretendemos reforzar la idea de que hay un tránsito obligado entre una forma de vida tradicional y campesina hacia una moderna y urbana. En realidad, la nuclearización de las familias no se debe a una forma de organización emanada de su urbanización, sino más bien obedece a factores como el tipo de migración que practican y al contexto familiar que los obliga a salir de sus lugares de origen. En el trabajo de campo gran parte de estos indígenas urbanos han señalado que se sienten "expulsados" de sus familias por problemas de herencia, horfandad, pobreza, entre otros. Es por ello que insistimos en la idea de reconsiderar el papel que juegan las relaciones afectivas entre las familias en la migración urbana y por supuesto en la reconfiguración extracomunitaria. Además, considerar a estos grupos nuclearizados ha representado todo un reto teórico y metodológico para la antropología contemporánea, ya que ha implicado el cuestionamiento del paradigma comunitario para abordar a los indígenas actualmente.

\section{LOS INDÍGENAS EN LA CAPITAL POTOSINA}

Según las estadísticas del Instituto Nacional de Geografía y Estadística (INEGI), en el 2005 residían en la capital potosina y su zona conurbada (Soledad de Graciano Sánchez) aproximadamente 4,236 hablantes de lengua indígena (HLI) pertenecientes a 31 grupos lingüísticos (INEGI 2005). Las lenguas mayormente habladas son las siguientes: náhuatl $(1,307)$, tének o huasteco $(577)$, otomí $(122)$ y mazahua (69) (Chávez 2010). Los dos grupos lingüísticos más numerosos proceden de la región Huasteca, principalmente de la parte que corresponde al mismo estado o bien a las de Veracruz e Hidalgo; esto indica que los indígenas urbanos en San Luis forman parte de una movilidad interestatal que sin duda alguna influye en el conocimiento previo que tienen de la capital. 
Los nahuas y tének se asientan regularmente de forma dispersa tanto en colonias periféricas como antiguas de la capital y recrean su etnicidad en términos más íntimos, es decir, dentro del espacio doméstico y reforzada por relaciones de parentesco. Muchos de éstos indígenas vivieron en cabeceras municipales de la Huasteca antes de llegar a la capital por lo que ahí adquirieron muchas de sus experiencias interétnicas y cierto capital cultural que emplean para vivir en la ciudad. La gran mayoría no usa la vestimenta tradicional y desplaza el uso de sus lenguas maternas por el español. Por esta razón es común encontrar que los hijos de éstos indígenas ya no hablan ni comprenden el náhuatl o tenek respectivamente. Por otro lado, tampoco tejen redes étnicas muy definidas en la ciudad, por lo regular las familias se identifican entre sí, se conocen pero no establecen mayor relación de ayuda mutua.

Siguiendo con los datos del INEGI, en el 2005, 60\% de la población HLI asentada en la ciudad mayor de 5 años desarrolla una ocupación laboral. Según el tipo de trabajo que realizan, la distribución porcentual resulta muy equitativa entre los que se dedican al empleo doméstico (13.89\%), los comerciantes o empleados del comercio (13.11\%), los vigilantes o trabajadores de la fuerza armada (12.65\%) y los artesanos o trabajadores de las fábricas (12.37\%) y los profesionistas (4.74\%) (Chávez 2010). Así, una característica por resaltar en San Luis es la diversificación de trabajos urbanos que esta población realiza, aunque también podemos identificar ciertos nichos laborales entre ambos grupos los cuales tienen estrecha relación con la forma en que se asientan en la ciudad. El servicio doméstico es el nicho laboral al que las mujeres nahuas y tének se integran laboralmente en 55\% y $36 \%$ respectivamente, mientras que el porcentaje más amplio de varones ocupados -principalmente nahuasse ubica en el servicio de vigilancia y fuerzas armadas (en el ejército o en el servicio privado como veladores).

Lo interesante de abordar a esta población indígena es que por sus características tanto residenciales como laborales han permanecido invisibles para las autoridades públicas, académicas y más aún para la población urbana en general. No se trata de los grupos congregados, corporados, organizados políticamente o que viven en 
condiciones de alta marginación urbana, los cuales han sido sumamente abordados por las investigaciones sociales; sino de indígenas cuyas formas de vida fuera de sus lugares de origen les han permitido mantener grados de cohesión étnica con pocas manifestaciones externas, más bien conformando comunidades con lazos afectivos fuertes dentro de sus hogares nucleares y dispersos.

\section{Comunidades AFEctivas QUe SOSTIENEN LA IDENTIDAD ÉTNICA}

Manuela y Araceli son madre e hija originarias de una comunidad tének del municipio de Aquismon en San Luis Potosí. Manuela arribó sola a la capital a finales de 1970 y se empleó en el servicio doméstico gracias al contacto de una patrona citadina que necesitaba una muchacha "de quedada". ${ }^{1}$ En sus visitas a la comunidad se embarazó de un joven a quien le ocultó el nacimiento de Araceli hasta después de varios años. Cuando nació Araceli regresaron a la comunidad de origen; sin embargo, Manuela decidió trasladarse de nuevo a la ciudad cuando llegó el momento de que su hija iniciara su etapa de escolarización. Araceli creció y estudió en un ambiente urbano, viviendo dentro de las casas de las patronas de su madre, rodeada de fuertes prejuicios hacia su origen étnico y la ocupación laboral de su madre. Se profesionalizó dentro del ambiente artístico como Educadora Musical y finalmente se casó con un músico alemán con quien vive en Suecia al lado de sus tres hijos. Aunque tanto Manuela como Araceli vivieron gran parte de su vida fuera de su lugar de origen, su pertenencia étnica no se ha quebrantado en gran medida debido a la fuerte conexión afectiva que mantienen con su comunidad, sus parientes y hacia ciertos referentes culturales. Incluso, ahora que ambas viven en países diferentes, la vinculación entre

${ }^{1}$ El término hace referencia a una modalidad del servicio doméstico en el que las empleadas se "quedan" a vivir en la misma casa de sus empleadores a diferencia de aquellas que trabajan de "entrada por salida", es decir, sólo unas horas. Otra término utilizado para definir este tipo de trabajo es el de "puertas adentro" y regularmente abarca una jornada laboral de 10 a 12 horas diarias con un solo día de descanso (Chaney y García 1993). 
ellas y su mundo étnico se ha reconfigurado pero continúa teniendo vigencia identitaria para ambas.

Desde que Manuela salió por primera vez de su comunidad a los 18 años siguió frecuentando a sus familiares de su comunidad de manera intensa. Su forma de vida y de trabajo en la capital potosina le ha permitido intercambiar periodos de residencia entre la ciudad y la comunidad. Cuando Manuela ha necesitado apoyo en la crianza de su hija, se cansa de los conflictos con las patronas, su situación económica ha sido difícil y ahora que sus padres están muy enfermos de salud, se establece algunos meses en su comunidad. Mientras su hija estuvo estudiando procuró limitar las estancias al periodo vacacional, pero después de que Araceli se fue a vivir a Alemania, Manuela prolongó hasta por seis meses sus estancias en su comunidad.

Cuando hay un encuentro directo con la familia y el lugar de origen puede llegar a darse un intercambio material y una reproducción significativa de rituales, tal como lo sugiere el concepto de "comunidades morales"; sin embargo, mientras esto no sucede por diferentes razones, la pertenencia a esa comunidad imaginada descansa en la fuerza de los lazos afectivos. Aunque haya una intención explícita de transmitir esta pertenencia a los hijos, cuando no hay una buena relación afectiva, los esfuerzos carecen de sentido. A Manuela y Araceli no sólo las ha mantenido unidas su sentimiento de sentirse diferente al resto de los habitantes de la capital sino también el manejo de ciertos referentes culturales que la madre ha logrado transmitir a la hija aun cuando esté fuera de su socialización secundaria cotidiana. Araceli sabe lo que para Manuela significa ir a su comunidad, atender a sus padres ahora enfermos, preparar la comida tradicional y protegerse de los malos espíritus que a veces las rodean. Cuando Araceli se casó en el 2005 realizó una boda tradicional en Puhuitzé. Los preparativos de la boda fueron supervisados por ambas aunque mucha gente de la comunidad se involucró también. La mayoría de los invitados fueron de la comunidad, algunas patronas de Manuela y amigos de Araceli de la capital y siete familiares de su esposo que viajaron desde Alemania. Ella usó un vestido de boda blanco con muchas flores en su cabeza y su abuelo materno fue quien la entregó en el altar. Los invitados comieron zacahuil (tamal 
de grandes dimensiones de uso ritual) y escucharon un grupo de huapango durante la fiesta. Araceli me mostró y describió con orgullo las fotos de este evento, especialmente donde aparece con sus "viejitos". Después, en cuanto llegó a Alemania realizó una pequeña ceremonia religiosa con la familia de su esposo en la que usó el mismo vestido de novia.

En cada uno de sus dos embarazos, Araceli ha financiado el viaje de su madre a Alemania para recibir su apoyo en los primeros días después de dar a luz. Esta práctica, poco común en el país donde ahora vive, forma parte de la estrecha relación que mantienen madre e hija en términos afectivos. Para Araceli, la presencia de su madre es importante ya que de manera práctica le transmite sus conocimientos sobre la crianza de los hijos y le ofrece un soporte emocional en esta etapa. Manuela ha pasado hasta tres meses viviendo en la casa de su hija en Alemania y conviviendo con la familia de su yerno.

Desde el 2005, Araceli visita cada año a su madre en San Luis Potosí, incluso algunas veces ha viajado dos veces al año. Por lo regular, ella viaja con sus hijos y se queda por más de un mes con su familia materna. La capital potosina sólo es un punto de encuentro con su madre, ya que $80 \%$ de su tiempo lo ocupa en visitar a sus abuelos en Puhuitzé. Ahí Araceli se involucra en las actividades cotidianas de su familia en la comunidad: en la elaboración de la comida, el cuidado de los abuelos, el acarreo del agua, la visita a los parientes, entre otras cosas. Para ella es importante que sus hijos conozcan y se familiaricen con su mundo tének desde pequeños. Ahí se siente contenta de que sus hijos exploren con libertad el campo, prueben la comida tradicional y escuchen hablar su lengua materna. En comparación con otros hijos de profesionistas tének en la capital, Araceli tiene un conocimiento profundo sobre la región donde nació (la Huasteca), sobre las formas tradicionales de curación o sobre la elaboración de la comida que preparan en su comunidad. En uno de mis encuentros con esta familia, Araceli acababa de tener un choque dentro del taxi que la transportaba hacia su casa. En cuanto llegó le pidió a su madre que la barriera con hierbas y le preparara un té para "curarse del espanto". Ella regularmente realiza estas prácticas cuando sus hijos están intranquilos en Alemania. 
Yo a mi hijo, cuando ni el sol lo calienta, que está chipil o de mal humor, pues le paso un huevo y mi marido me dice "si tú crees en eso pues tu mente te ayuda", yo le digo que como buen científico todo lo que no puede experimentar no vale. Pero dicen que el espíritu se queda en el lugar donde te espantan y te puedes hasta morir del susto, dejas de comer o te da diarrea. Son cuestiones que uno no conoce y a veces no crees hasta que lo experimentas.

En la capital la relación con otros hablantes de tének es inexistente. Su espacio de trabajo, es decir, la casa de las patronas, fue por muchos años también el de residencia de ambas mujeres por lo que pasaron gran parte de su vida limitando la recreación de su espacio étnico mediante las visitas que realizaban a su comunidad. A pesar de que la mayor parte de la población hablante de tének que actualmente reside en la capital es femenina y labora en el empleo doméstico, las trayectorias de migración y el tipo de residencia aislada no han permitido la conformación de redes que refuercen la pertenencia étnica. Es por ello que los rituales y demás actividades simbólicas que alimentan la pertenencia no trascienden el espacio íntimo de la familia nuclear y en todo caso se refuerza mediante una conexión directa -sostenida por lazos afectivos-con la comunidad de origen. Esta dinámica poco común para la mirada antropológica es la que explica en gran parte la visibilidad tardía de estos grupos en comparación con aquellos que crean comunidades holísticas en los contextos urbanos. Más que conformar "comunidades morales", se conforman "comunidades afectivas" que operan de forma muy íntima en el seno de las familias nucleares fuera de sus lugares de origen.

Conforme iba conociendo la vida de esta familia, especialmente después de comentar y observar sus referentes étnicos, iba creciendo mi interés por saber cómo alimentan esta identidad moviéndose en espacios tan diversos. Especialmente en el caso de Araceli me llegué a preguntar varias veces porqué una mujer con una conexión afectiva fuerte hacia su mundo étnico decide vivir tan lejos de su comunidad y su familia. En varias ocasiones, Araceli me comentó que no estaba segura si haberse casado con un extranjero y verse obligada a vivir muy lejos de México, de Puhuitzé y de sus familiares había sido 
una buena decisión. Sin embargo, conforme me fui adentrando en su vida pude darme cuenta que aunque actualmente en términos emocionales resulta difícil alejarse físicamente de su mundo, para Araceli tener un anclaje en el extranjero ha significado una estrategia para formar una vida alejada de las relaciones de discriminación étnicas o de clase que existen en México, además su nivel de vida en Alemania le ha permitido reforzar sus relaciones en términos materiales, culturales y afectivos con su familia tanto en la capital potosina como en su comunidad de origen.

Al conocer parte de su grupo de amigos en la capital potosina, percibí que Araceli se sentía cómoda e identificada con otros jóvenes que conoció en la Escuela Estatal de Música, es decir, dentro del ambiente artístico que valoraba en términos positivos sus diferencias culturales. No obstante, al momento de construir relaciones personales de mayor intensidad, como lo es una relación de pareja, Araceli no logró concretarlo en la ciudad y eligió casarse con un músico extranjero. Ella no tuvo relaciones de noviazgo serias en la capital potosina por sentir temor a que los chicos descubrieran y se burlaran de su procedencia indígena y de que su madre era una empleada doméstica. Después de que viajó a Alemania y conoció a su futuro esposo dentro del ambiente musical, sintió que podía entablar una relación con la confianza de que sería aceptada con todo su contexto familiar. El hecho de casarse con un alemán que valora positivamente su diferencia cultural y que no participa de los prejuicios étnicos y de clase que caracterizan las relaciones asimétricas en México le ha permitido asumir con menos tensión su adscripción étnica en su vida cotidiana y familiar. Como ocurre en el caso de mujeres migrantes transnacionales, este matrimonio de Araceli podría calificarse de hipergámico ya que le permitió acrecentar sus posibilidades de promoción social, de calidad de vida y de poder adquisitivo que difícilmente habría alcanzado en el contexto potosino o de la Huasteca (Roca 2007; Bodoque y Soronellas, s/a).

En este caso, no sólo logró superar las barreras de clase, sino también las barreras raciales que distinguen la relación entre indígenas y mestizos en México. Por supuesto que Araceli experimenta ciertos conflictos culturales en Alemania pero sin la carga peyorativa que 
significa ser indígena en su propio país. En Alemania se encontró con un ambiente que es muy contrastante para ella en términos culturales, lo cual la ha llevado a negociar en el día a día su identidad como mexicana y como indígena tének; sin embargo, ella se siente más cómoda en esta situación que viviendo bajo el estigma de su etnicidad en México.

En su casa en Alemania, Araceli y su esposo han llenado el cuarto de su primer hijo con imágenes simbólicas de México y los indígenas. En uno de los muros de la habitación los padres pintaron un ferrocarril con árboles, entre ellos un águila, un nopal y flores de cempazuchitl. También hay un cuadro de una indígena vendiendo flores en la calle. Sus hijos tienen dos nombres, uno de ellos es nahua. Aunque ella pertenece al grupo tének, como ya explicamos anteriormente, la lengua náhuatl en la región Huasteca tiene un predominio numérico y valorativo que lo hace ser usado para reafirmarse étnicamente más allá de las diferencias entre los grupos.

En uno de sus cumpleaños en Alemania, Araceli organizó un festejo en su casa con un mariachi en vivo y preparó tamales para sus invitados alemanes. Por lo regular, ella viste blusas de manta bordadas con motivos florales y colores muy vivos y aunque no forman parte del traje tradicional del grupo étnico al que pertenece, sí son parte del imaginario folklorizado sobre los pueblos indígenas en México que se proyecta en el extranjero y que Araceli emplea para remarcar su etnicidad. En San Luis nunca la vi usar estas blusas, por lo regular usaba tenis o botas de campo, pantalones y sudaderas.

En Alemania, Araceli no trabaja y por lo tanto no recibe ingresos a pesar de ser una profesionista en la educación musical, sin embargo, su situación económica allá le permite enviar recursos económicos para apoyar a su familia en México. Debido a sus problemas en las piernas, Manuela tiene dificultades para trabajar en el servicio doméstico, por lo que Araceli le deposita dinero en una cuenta bancaria. Con este dinero, Manuela paga la renta de una casa, se mantiene en la capital y paga sus viajes frecuentes a su comunidad en la Huasteca, además de arreglar los problemas de salud de sus padres. Cada año que Araceli viaja a Puhuitzé se encarga de solucionar los asuntos legales de las tierras de "sus viejitos" y últimamente está 
apoyando a su madre en la compra de un solar en la comunidad para que se regrese a vivir ahí ahora que ella se encuentra en el extranjero y sus abuelos están delicados de salud.

Ya estando en Alemania yo decía "quiero a mi mamá y a mis viejitos", lo que más me duele son mis viejitos, él tiene 89 y mi abuelita 79 y están enfermos de artritis y mi mamá también está enferma del pie, eso me cuesta mucho trabajo. Siempre estoy tratando de ayudar a mi mamá y a mis abuelos y es difícil porque es mi única familia, porque la familia de mi papá ni sus luces, ellos que se hagan bolas. Para mí eso es lo más duro, porque en Alemania tengo todas las comodidades que quiero, tengo dónde vivir, tengo qué comer, puedo viajar a donde quiero, a mi marido le va muy bien.

Si bien, en esta nueva etapa de su vida familiar Araceli ha transformado sus expectativas laborales, ahora vive su etnicidad en términos más íntimos empleando sus recursos para reafirmarse en su nuevo espacio de vida y reforzar sus lazos afectivos mediante el apoyo desde afuera a su familia dispersa entre la ciudad y la comunidad.

\section{EL DETERIORO DE LAS RELACIONES AFECTIVAS EN EL NIVEL FAMILIAR Y LA IDENTIDAD ÉTNICA RECHAZADA}

La familia Sánchez López está conformada por un matrimonio mixto, Jesús es un maestro bilingüe originario de una comunidad nahua de Tamazunchale y Clara -la esposa- es una mestiza originaria de la misma región Huasteca pero de la cabecera municipal de Tancanhuitz que no concluyó la educación básica. Llegaron a la capital potosina en 1991 y actualmente tienen cuatro hijos los cuales crecieron en contextos de socialización diversos, los primeros dos en la comunidad de origen del padre -Fausto y Lucía- mientras que los últimos -Héctor y Josué- en la capital potosina. Las relaciones interpersonales en la comunidad de origen del padre, así como la trayectoria de migración de la familia han impactado en la adscripción étnica tanto del padre como de los hijos.

Jesús salió de su comunidad a una edad muy temprana -9 añosdebido a que su madre había muerto y su padre estaba formando 
una nueva familia en la que se sintió rechazado por no ser de sangre directa. Regresó después de profesionalizarse en la docencia bilingüe con la intención de ayudar al resto de sus hermanos para que siguieran su mismo camino, invirtió su sueldo de años en la compra de tierras y ganado y ocupó cargos comunitarios además de colaborar en la gestión de caminos y escuelas; sin embargo, los conflictos familiares nunca terminaron y fueron la causa principal de que él decidiera salirse definitivamente de su comunidad y al parecer adquiriera fuertes problemas con el alcohol. Fue en este contexto de ruptura familiar que Jesús decidió radicar en la capital potosina y ejercer su profesión docente por un corto tiempo, hasta que fue cesado definitivamente del sistema educativo por problemas personales.

Los dos hijos mayores pasaron los primeros años de su infancia en la comunidad nahua de su padre. Sin embargo, la relación fracturada de su padre con su familia directa impidió que asumieran sin conflicto su pertenencia étnica. Su madre, Clara, tampoco era bien aceptada por la familia de su esposo por ser mestiza. Los recuerdos que ambos hijos tienen de su vida en la comunidad no son positivos, por ejemplo, Lucía señalaba no sentir afecto por su abuelo paterno porque "era muy feo. Mi mamá nos quería acercar pero él no nos quería. No nos daba ni un plátano, nos decía que nos fuéramos a otro lado a jugar, su mujer menos nos quería". Ellos vivieron la transición laboral de su padre y el deterioro de sus relaciones familiares, ya que en su memoria guardan recuerdos de cuando Jesús era un maestro prestigiado a quien muchas personas iban a visitar para pedirle ayuda y cómo a partir de sus problemas familiares "se tiró al vicio del alcohol", se volvió violento con ellos y fue cesado de su plaza como docente.

En estos momentos de crisis familiar, Jesús se encargó de transmitir una memoria familiar deteriorada que sin duda impactó negativamente en la adscripción étnica tanto de Lucía como de Fausto. El discurso genealógico es una forma particular de dar sentido al pasado y se relaciona con la construcción de la identidad social. Cada vez que Jesús llegaba tomado a casa les hablaba en náhuatl, escuchaba huapangos y les contaba partes de su dolorosa vida en la comunidad y la traición de su familia. Así, Fausto, el hijo mayor, fue 
relacionando el alcoholismo de su padre con las tradiciones de su gente en la Huasteca, lo cual lo llevó a despreciar los elementos culturales de esta región y todo lo que tuviera que ver con la familia de su padre.

Algo que empecé a odiar es que él tenía sus casetes de huapangos y cada vez que llegaba tomado los ponía o hablaba de que me iba a dejar su plaza y empecé a odiar eso [...] siempre con sus huapangos, a veces era agradable, no siempre, a veces lloraba, a veces nos platicaba escenas de su niñez, de su trabajo [...] Escuchar los huapangos o la música tradicional de la Huasteca para mí era vincularlo con una persona que no tenía fuerza, una persona alcohólica, fui teniendo cada vez rencor hacia lo que todavía es parte de mi historia [...] también empecé a odiar esa parte de la Huasteca, de mi historia, porque así dejaron a mi papá.

La desarticulación familiar se agudizó con el arribo de la familia a San Luis Potosí, al llegar a la capital experimentaron fuertes crisis económicas, problemas de inserción laboral en ambos padres, hasta que Clara finalmente asumió la jefatura económica de la familia. Fue en este momento cuando los hijos experimentaron mayor rechazo afectivo hacia su padre y todo lo que tuviera ver con "su mundo nahua y de la Huasteca". Especialmente Fausto, quien asumió el papel de padre para sus hermanos menores e incluso estuvo tomando terapia psicológica para superar los problemas en casa. Lucía tenía fuertes discusiones pero se vio menos afectada emocionalmente. Esta situación, aunada a la discriminación que tenían en espacios de interacción como la escuela, impactó negativamente en su pertenencia étnica.

Aún con estos conflictos, Fausto y Lucía no rompieron completamente con el lazo que los une e identifica con su padre. Ambos eligieron una carrera vinculada a la profesión de Jesús: Fausto estudió una licenciatura en matemáticas con orientación hacia la enseñanza y Lucía intentó ingresar a la Normal para también ser maestra, pero no la aceptaron y finalmente se decidió por la abogacía. Esta última elección se debe al interés de Lucía por defender legalmente en un futuro a su padre por la pérdida de sus propiedades en Meca- 
tlán y de su plaza en la ciudad. Incluso cuando estaba a punto de terminar la carrera, regresó a esta comunidad después de casi quince ańos de no hacerlo para conocer a fondo la situación con la familia y ayudar a su padre, aunque en los hechos logró muy poco. Fausto una vez que concluyó sus estudios universitarios, también regresó a trabajar a la Huasteca para poder demostrarle a la familia paterna que ellos salieron adelante sin su apoyo, que eran unos profesionistas exitosos.

Cuando salí de la carrera dije "yo algún día voy a regresar (a la Huasteca) y va a ser de un modo diferente, voy a limpiar el nombre de mi papá”. Yo creo que con mi hermana fue igual, esto determinó el sentido de nuestras carreras, por ejemplo, mi hermana decía que quería ser abogada para ver qué injusticias le hicieron a mi papá en su carrera y en su tierra.

Por su parte Lucía comenta:

Quería ser maestra porque veía como admiraban a mi papá y ayudaba a la gente pero como ya no pude entrar a la Normal, has de cuenta que vi (en la carrera de Derecho) una forma de ayudar a la gente y a mi papá.

En la etapa de universitarios ambos reafirmaron su ascendencia étnica y trataron de reconciliar la relación fracturada con su padre. En el 2000, Fausto -junto con otro amigo- creó un proyecto de difusión de la ciencia en el medio rural. Después de pasar unas semanas en localidades rurales del altiplano potosino resucitaron sus recuerdos de vida en la comunidad y empezó a construir en su memoria puentes de identificación con el grupo nahua. De ser un proyecto de difusión se convirtió en un proyecto de atención a las comunidades nahuas de la Huasteca que en términos personales para Fausto representó un reencuentro con su "origen indígena". El papel de Jesús fue fundamental para este tránsito, ya que él hablaba con su hijo para que dirigieran sus acciones hacia las comunidades nahuas de la Huasteca. Él también les sugirió ponerle un nombre nahua a la agrupación. Fausto le propuso a su papá impartir clases de náhuatl a universitarios de la capital como parte de las actividades culturales 
del grupo. Esto le ayudó mucho a Jesús a recomponer su relación con sus hijos y sobre todo le ha permitido vivir su etnicidad en términos menos conflictivos en la ciudad. Poco a poco se ha posicionado como el único maestro de náhuatl en la ciudad y ahora organiza cursos en universidades públicas y privadas en San Luis.

Por su parte, los dos hijos menores -Héctor y Josué- crecieron en un ambiente totalmente urbano pero además dentro de una colonia con altos índices de violencia y en un contexto familiar muy conflictivo. Su vida en la ciudad la describen como marcada por una desarticulación familiar derivada del desempleo de Jesús, su acentuado gusto por el alcohol, sus tratos violentos hacia ellos y la desatención hacia su desempeńo escolar. Los dos crecieron con poca supervisión en casa, Clara trabajaba hasta doble jornada por lo que pasaban mucho tiempo solos en casa, desde pequeños se iban juntos a la escuela caminando y por las tardes se salían a la colonia para reunirse con sus amigos.

$\mathrm{Al}$ ser una familia mixta, la reproducción de la identidad étnica hacia los hijos recae sobre el padre principalmente, sin embargo, cuando media una relación conflictiva entre ambos se cortan los canales afectivos que soportan la transmisión efectiva de la etnicidad. A diferencia de sus dos hermanos mayores, quienes vivieron dos etapas fundamentales de la historia familiar al crecer primero en la Huasteca y luego trasladarse a la ciudad, a los menores les tocó desarrollarse en una etapa laboral difícil para su padre así como en la jefatura económica de su madre en la capital y las tensiones familiares que se derivaron de estos dos hechos. Tanto Fausto como Lucía experimentaron el descender de un nahua profesionista en un ambiente donde esto les brindaba un reconocimiento social como familia; sin embargo, para Héctor y Josué, esta etapa no es parte de su vida personal. Cada periodo vacacional, viajaban a la Huasteca junto con un tío de su madre, y se quedaban en Tancanhuitz, la cabecera municipal donde vive la familia de su madre. Allá pasaban semanas conviviendo con sus primos o visitando los arroyos, pero hasta la fecha no conocen la comunidad nahua de su padre, mucho menos a sus parientes.

La relación directa que mantienen con Jesús es lejana. Conocen muy poco de su historia personal, por ejemplo, Héctor está estu- 
diando para ser maestro de matemáticas y cuando le comenté que su papá había estudiado lo mismo se asombró porque no tenía conocimiento. Héctor guarda en su memoria varios momentos de violencia intrafamiliar derivados del alcoholismo de su padre. Eso le genera un fuerte distanciamiento con él en el plano emocional que refleja en su constante anhelo por "salirse de su casa".

Mediante los dilemas de reproducción étnica de esta familia observamos cómo entre los hijos operan diferencias generacionales a la hora de asumir la adscripción étnica. Los mayores no se sienten "ni indígenas ni mestizos" porque les costó trabajo integrarse tanto a la comunidad nahua de la Huasteca como a la capital potosina. Esto les ha llevado a vivir su pertenencia de manera conflictiva; mientras que los hijos menores no sienten ningún tipo de filiación étnica por sus entornos de socialización y desarticulación familiar en la que crecieron. Sin embargo, también es importante señalar que los niveles de adscripción étnica también se transforman a lo largo de los ciclos de vida de un individuo; si bien durante la etapa adolescente todos los hijos se alejaron del mundo étnico debido a los conflictos con su padre, en cuanto se convirtieron en jóvenes universitarios experimentaron un replanteamiento de su pertenencia y buscaron una reafirmación que se expresó en una reconciliación afectiva en el nivel familiar. De esta manera observamos que entre los migrantes y sus descendientes, la pertenencia étnica no sólo depende de los escenarios de contacto o interacción, sino de los ciclos de vida, es decir, no sólo es situacional, sino que se transforma a lo largo del tiempo en el ciclo de un individuo.

\section{Conclusiones}

La reciente producción científica sobre la migración indígena se ha centrado en cómo se transforma la vida material y cultural de esta población a partir de su arribo a la ciudad, especialmente en las transformaciones derivadas de las nuevas ocupaciones laborales, la distribución espacial de los migrantes, la conformación de redes y de organizaciones políticas, entre otras. Todo esto ha puesto en el foco de la atención los dilemas de la reproducción étnica fuera de los 
lugares de origen. Los indígenas urbanos no siguen un patrón único para reconfigurarse como grupo en las ciudades, más bien llevan a cabo diversas acciones que dependen de circunstancias tanto en sus lugares de origen como en los de residencia. En este trabajo se ha enfatizado que el tipo de relación familiar así como la calidad afectiva entre sus miembros es un elemento que tiene gran influencia en este proceso.

La resignificación étnica en contextos migratorios sin duda no adquiere las mismas características cuando se trata de sujetos que migran de manera individual que cuando hablamos de familias completas. Es en el seno de las familias que se recrean las prácticas, símbolos y representaciones que soportan la etnicidad. Ahí es donde se materializan los conflictos y tensiones propias de la socialización intercultural que viven estos grupos y quedan manifiestas las diferencias generacionales entre padres e hijos. También es en las familias donde los padres hacen evidente el futuro que desean para sus hijos, un futuro que define el proyecto promocional en el que la escolarización resulta estratégica (Romer 2003). Finalmente, es dentro de este entorno donde se genera y renueva el soporte afectivo que da sentido a la pertenencia étnica de cada uno de los miembros, principalmente cuando hablamos de grupos que viven de manera dispersa en contextos urbanos, como ocurre en el caso de los nahuas y tének.

La continuidad de la identidad étnica entre los grupos migrantes dispersos depende en gran medida de la calidad de las relaciones afectivas que tengan con sus parientes y comunidades de origen. En los casos en los que las relaciones familiares y comunitarias han sido rotas por diferentes conflictos, los sujetos tienden a evitar la interacción con las comunidades de origen por lo que no encontramos redes de paisanazgo que los vinculen y además la transmisión hacia las segundas generaciones suele ser de menor intensidad. Sin embargo, cuando las relaciones afectivas entre padres e hijos es de buena calidad, la reproducción étnica suele ser menos conflictiva aun cuando fuera de la familia nuclear urbana no exista un soporte material y cultural que lo alimente. En este sentido, es la "cultura íntima" -en palabras de Epstein- la que genera esta capacidad de aglutinamiento 
y ésta se origina justo por la interacción cotidiana de los miembros de un colectivo, en este caso nos referimos a la familia, la cual media todas sus acciones y relaciones a través de los afectos. Así pues, vemos que no todas las etnicidades urbanas se conforman en discursos explícitos que denotan una reivindicación en acción.

En el caso de algunos grupos indígenas, sus formas de vida holística les ha permitido mantener-aunque con cambios- el papel de la familia extensa a través de sus formas de residencia conglomerada y las redes de paisanazgo que reconstruyen en la ciudad. Pero, ¿qué sucede en el caso de los grupos indígenas que viven en un contexto en el que no mantienen la forma de vida holística, como es el caso de los tének y nahuas que habitan la capital potosina? En ambos casos, por lo regular las familias nucleares se insertan de manera dispersa a lo largo de la ciudad mientras mantienen poco contacto con los paisanos. Esta situación llevaría a pensar que la nuclearización de las familias está relacionada con la reconfiguración -incluso con la pérdida paulatina- de la identidad étnica. Sin embargo, en uno de los casos analizados - la pequeńa familia nuclear representada por Manuela y Araceli- observamos que la identidad étnica sigue operando con fuerza en sus vidas después de casi tres décadas de vivir en la ciudad. Ellas han construido su propia "comunidad afectiva" que se sostiene a través del contacto con la familia extensa en la comunidad de origen tének.

Sin embargo, también esta afectividad se manifiesta en términos negativos, justo cuando la "renuncia" a la identidad étnica va cargada de experiencias de enojo, rechazo, o frustración, tal como lo muestra el caso de la familia Martínez López. Si se entiende este abandono como una afectividad negativa se reconoce entonces que la identidad étnica continúa operando al interior del individuo o del grupo. Esto implica reconocer que los atributos de la etnicidad siguen siendo un referente identitario aunque sea para renunciar a ellos. Este proceso ocurre en el contexto de las relaciones asimétricas que operan en un sistema interétnico. Específicamente en el caso de los indígenas que migran a la ciudad y convierten a este espacio en su lugar de residencia, las relaciones con el grupo mayoritario y mestizo producen emotividades que influyen en la reproducción de la 
identidad étnica al interior de su familia. Ya que las condiciones materiales y sociales que operan en la ciudad son distintas con respecto a las que operan en términos comunitarios, resulta muy difícil que los hijos de estos profesionistas indígenas lleguen a identificarse étnicamente si no hay una sólida relación afectiva con los emblemas identitarios en el nivel familiar.

Es en las relaciones interpersonales donde se viven con tensión los cambios estructurales, en el caso de las familias indígenas que llegan a la ciudad, estas relaciones cargadas de afecto pueden llegar a ser el marco determinante para la reproducción identitaria. El tipo de relación afectiva que se mantenga entre los miembros opera con más fuerza en la reproducción o transmisión de dimensiones subjetivas de la realidad, como lo es el apego a cierta identidad étni$\mathrm{ca}$, un apego que puede resultar positivo y otras veces con una fuerte carga de rechazo.

\section{BiBLIOGRAFÍA}

ArIzA, Marina, "Migración, familia y transnacionalidad en el contexto de la globalización: algunos puntos de reflexión" en Revista Mexicana de Sociología, vol. 64, núm. 4, octubre-diciembre, 2002, 53-84.

BARTOlOMÉ, Miguel, Gente de costumbre y gente de razón. Las identidades étnicas en México, México, INI, Siglo XXI, 1997.

BESTARD-CAMPS, Joan, "La familia: entre la historia y la antropología” en Papers. Revista de Sociología, 36, Barcelona, 1991, 79-91.

Chaney, Elas y Mary García Castro, eds., Muchacha, cachifa, criada, empleada, empregadinha, sirvienta y... más nada. Trabajadoras domésticas en América Latina y el Caribe, Venezuela, Editorial Nueva Sociedad, 1993.

Chávez González, Mónica, Familias, escolarización e identidad étnica entre profesionistas tenek y nahuas en la ciudad de San Luis Potosí, tesis de doctorado en Ciencias Sociales, Guadalajara, Ciesas Occidente, 2010.

Durin, Séverine, "Indígenas en Monterrey: redes sociales, capital social e inserción urbana”, en Pablo Yanes, Virginia Molina y Óscar 
González, El triple desafio. Derechos, instituciones y politicas para la ciudad multicultural, México, Sedesol, Dirección General de Equidad y Desarrollo Social, 2006, 163-198.

, "Introducción", en Séverine Durin, coord., Entre luces y sombras. Miradas sobre los indigenas en el Área Metropolitana de Monterrey, México, Ciesas, CDI, 2008, 21-78.

En Monterrey hay trabajo para mujeres. Procesos de inserción de las mujeres indigenas en el Area Metropolitana de Monterrey, Monterrey, Unesco, Ciesas, CDI, 2009.

Epstein, A. L., Ethos and Identity, Londres, University Printing House Cambridge, 1978.

Glazer, Nathan y Daniel P. Moynahan, Ethnicity theory and experience, Harvard University Press, 1975.

Malkin, Victoria, "Reproduction of gender relations in the Mexican community of New Rochelle, NY", ponencia presentada en el xix Coloquio de Antropología e Historia Regionales, 22-24 de octubre, Zamora, El Colegio de Michoacán, 1997.

Martínez Casas, Regina y Guillermo de la Peña, "Migrantes y comunidades morales. Resignificación, etnicidad y redes sociales en Guadalajara", en Revista de Antropología Social, vol. 013, Espańa, Universidad Complutense de Madrid, 2001, 217-251.

Rojas, Angélica, Entre la banca, la casa y la banqueta. Socialización y matemáticas entre los niños otomies que viven en la $Z M G$, tesis de doctorado en Ciencias Sociales, Guadalajara, Jalisco, Ciesas Occidente, 2006.

ROMER, Martha, ¿Quién soy?: la identidad étnica en la generación de los hijos de migrantes indígenas en la zona metropolitana de la Ciudad de México, tesis de doctorado en Antropología, México, INAH, ENAH, SEP, 2003.

Salvia, Agustín, "La familia y los desafíos de su objetivación: enfoques y conceptos", en Estudios Sociológicos, XIII, 37, enero-abril, México, El Colegio de México, 1995, 143-162.

Velasco OrTIz, Laura, El regreso de la comunidad: migración indigena y agentes étnicos (Los mixtecos en la frontera México-Estados Unidos), México, El Colegio de México, El Colegio de la Frontera Norte, 2002. 
, Desde que tengo memoria. Narrativas de identidad en indígenas migrantes, Tijuana, El Colegio de la Frontera Norte, Fondo Nacional para la Cultura y las Artes, 2005.

FECHA DE RECEPCIÓN DEL ARTí́CULO: 21 de noviembre de 2011 FECHA DE RECEPCIÓN DE LA VERSIÓN FINAL: 16 de abril de 2012 